\title{
Metodologias para alocação equitativa de recursos federais a estados e municípios ao redor do mundo: uma revisão integrativa - primeiros resultados
}

\author{
Bruno Lopes ZANETTA ${ }^{(1)}$ \\ Leonardo CARNUT
}

Recebido: 28 jan 2019 Aceito: 10 fev 2019

Autor de correspondência: zanetta.bruno@gmail.com Conflito de interesses: Os autores declaram não haver nenhum interesse profissional ou pessoal que possa gerar conflito de interesses em relação a este manuscrito.

${ }^{(1)}$ Faculdade de Saúde Pública, Universidade de São Paulo - USP, São Paulo, SP, Brasil.

\section{Resumo}

O direito à saúde universal, integral e gratuita, embora positivado pela Constituição Federal de 1988 (CF-88), em seus artigos de 196 a 200, é de difícil efetivação prática. Tendo em vista, para além das dimensões continentais do Brasil, a complexa relação entre os três níveis da Federação, há uma profunda desigualdade de renda, que se manifesta tanto nas classes sociais, quanto entre as várias regiões, estados e municípios do país que desafiam a alocação. Ao longo da história de criação e construção do Sistema Único de Saúde - SUS, o tema do financiamento tem sido central para o debate e a defesa da garantia constitucional. A esse respeito, a CF-88 indicou que a saúde pública deveria ser financiada, em 1989, com 30\% dos recursos do orçamento da seguridade social e, nos anos subsequentes, de acordo com o estabelecido nas respectivas Leis de Diretrizes Orçamentárias - LDO). Tais recursos financeiros, contudo, nunca foram garantidos à saúde pública brasileira, cujos defensores lutam, desde então, pela definição de um piso mínimo de orçamento para área. Ao contrário do que determina a Carta Magna, os recursos para garantir o financiamento e o pleno funcionamento do SUS foram sendo, ao longo do tempo, restringidos pelas normas supervenientes. Nesse sentido, a reforma previdenciária realizada pelo Governo Fernando Henrique Cardoso, em 1993, eliminou os repasses para a saúde. Por sua vez, a criação da Desvinculação de Receitas da União - DRU, no ano 2000, diminuiu a quantidade de recursos vinculados no orçamento público em 20\%, sendo que a criação da Contribuição Provisória sobre Movimentação Financeira - CPMF, em 1997, já não havia incorporado novos recursos à saúde, como fora a ideia inicial. Apesar de a Emenda Constitucional no 29 (EC-29) ter vinculado recursos públicos para gastos com ações e serviços de saúde, a norma não foi clara quanto à definição de o que seriam tais ações e serviços de saúde. Assim, de 2003 a 2011, a omissão legislativa em regulamentar a EC-29 fez com que o setor perdesse importante volume de recursos. Finalmente, com a publicação da Lei Complementar no 141 (LC-141), em 2012, foi feita a necessária regulamentação da EC-29 e, portanto, foram determinados (a) quais são as ações e os serviços públicos de saúde, (b) estabelecidos os percentuais mínimos para aplicação de União, estados e municípios em saúde, e (c) estabelecidas regras para a transferências de recursos para financiamento da saúde entre os entes 
federados. Dessa maneira, um importante artigo da LC-141 estabelece que: "Art. 17. O rateio dos recursos da União vinculados a ações e serviços públicos de saúde [...] observará as necessidades de saúde da população, as dimensões epidemiológica, demográfica, socioeconômica, espacial e de capacidade de oferta de ações e de serviços de saúde e, ainda, o disposto no art. 35 da Lei no 8.080, de 19 de setembro de 1990, de forma a atender os objetivos do inciso II do $\S 3^{\circ}$ do art. 198 da Constituição Federal. §1 O Ministério da Saúde definirá e publicará, anualmente, utilizando metodologia pactuada na comissão intergestores tripartite e aprovada pelo Conselho Nacional de Saúde, os montantes a serem transferidos a cada Estado, ao Distrito Federal e a cada Município para custeio das ações e serviços públicos de saúde". Ressalte-se, neste ponto, que a LC-141 determina que o governo federal estabeleça e torne pública, todos os anos, uma metodologia para que seja realizada a distribuição dos recursos financeiros federais para financiamento de ações e serviços públicos de saúde a estados e municípios. Tal metodologia deve considerar as características de cada território em várias dimensões, assim como as necessidades de saúde da população, conforme determinam, inclusive, o artigo 35 da Lei 8.080/1990, conhecida como Lei Orgânica da Saúde. Novamente, assim como em outros momentos na história da luta pelo financiamento do SUS, esse importante artigo da LC-141 ainda carece de regulamentação por parte do Executivo federal, fazendo com que o cálculo para a transferência dos recursos da União aos estados e municípios se mantenha com base no valor do ano anterior, corrigido pela variação nominal do PIB. Há diversas experiências no mundo que visam ao desenvolvimento de metodologias para alocação equitativa de recursos para a saúde. Nesse sentido, é preciso retomar o debate sobre equidade e sobre necessidades de saúde, visto que o objetivo principal de todas essas metodologias deve ser a distribuição dos recursos financeiros da forma mais equânime possível, considerando as diferenças censitária, geográfica, populacional e epidemiológica de cada região, cada localidade de um determinado país, sobretudo um país de dimensões como as do Brasil. Objetivo: o objetivo deste estudo é revisar, analisar e comparar criticamente o que foi produzido sobre as experiências governamentais, no Brasil e no mundo, para alocação de recursos financeiros federais a estados e municípios, sobretudo em sistemas públicos e universais de saúde. Método: a pesquisa é uma revisão integrativa da literatura nacional e internacional, que busca levantar a produção científica disponível acerca da alocação de recursos financeiros de governos centrais a entes subnacionais, por meio de busca sistematizada em três plataformas de bases de dados da Saúde: Bireme, PubMed e Scopus. A partir da definição da pergunta de pesquisa, foram definidos quatro polos temáticos de interesse, a saber: (a) alocação de recursos; (b) financiamento da saúde; (c) governo; e (d) SUS. Em seguida, para as três plataformas foi utilizada a técnica do funil, combinando e testando diversos descritores com operadores booleanos " $A N D^{\prime}$ e " $O R$ ". Tendo em vista a necessidade de realizar as buscas tanto em língua portuguesa, quanto inglesa, os descritores foram selecionados por meio 
do DeCS e dos MeSh Terms, sendo que, para a seleção dos artigos e estudos a serem analisados, serão escolhidos apenas aqueles escritos em português, inglês e espanhol. Considerações finais: em primeiro lugar, para a busca na plataforma da Bireme, identificaram-se a 182 estudos, cuja sintaxe final é: (mh:("ALOCACAO de recursos" or "ALOCACAO de recursos em saude" or "ALOCACAO de recursos para a atencao a saude")) AND (mh:("FINANCIAMENTO" or "organizacao do FINANCIAMENTO" or "FINANCIAMENTO da saude" or "FINANCIAMENTO governamental" or "FINANCIAMENTO publico")) AND (mh:("federalismo" or "GOVERNO do municipio" or "GOVERNO estadual" or "GOVERNO federal" or "GOVERNO LOCAL" or "regionalizacao") or ("sistemas locais de saude" or "SISTEMAS DE SAUDE" or "descentralizacao")). Nota-se, a partir de uma análise preliminar, que há poucos estudos ou artigos que tratam do tema, sendo que a maior parte dos que abordam a temática se referem à realidade brasileira. Em segundo lugar, para a busca na plataforma da PubMed, foram identificados 123 estudos, cuja sintaxe final é: (( Health Resources[MeSH Terms] OR Resource Allocation[MeSH Terms] OR Financing, Government[MeSH Terms] OR Health Care Rationing[MeSH Terms] OR Financial resources in health[MeSH Terms])) AND Local Government[MeSH Terms]) AND (Public Assistance[MeSH Terms] OR universal coverage[MeSH Terms] OR National Health Programs[MeSH Terms]). Por fim, para a busca na plataforma da Scopus, foram identificados 155 estudos, cuja sintaxe final é: $K E Y$ ( "health care rationing" ) OR KEY( "resource allocation" ) $O R K E Y$ ("equity in resource allocation" ) OR KEY("health resources" ) $O R$ KEY ("financial resources in health" ) AND KEY ("Financing, Government" ) OR KEY( "Local Government" ) AND KEY("Public Assistance" ) OR KEY( "Universal Coverage" ) OR KEY("National Health Programs") OR KEY("health systems" ). Nessas duas últimas plataformas, também após análise preliminar dos resultados, percebe-se que há poucos estudos que abordam a temática desta pesquisa.

Descritores: Alocação de Recursos; Equidade na Alocação de Recursos; Recursos Financeiros em Saúde; Financiamento Governamental; Sistemas Locais de Saúde; Sistemas de Saúde. 